\title{
Outreach Activities and Teacher Training Programs in Turkey
}

\author{
Sinan Alis ${ }^{123}$ \\ Address: ${ }^{1}$ Istanbul University, Science Faculty, Department of Astronomy and Space Sciences, 34134 \\ Beyazit, Istanbul, Turkey \\ ${ }^{2}$ Istanbul University Observatory Research and Application Center, 34134 Beyazit, Istanbul, \\ Turkey \\ ${ }^{3}$ Turkish Astronomical Society (TAD) \\ E-mail: alis@istanbul.edu.tr
}

\begin{abstract}
In this paper, outreach activities and teacher training programs that are held in Turkey are presented. There are star parties, public nights, summer schools and open house events among public outreach activities in astronomy. More than a decade special courses and concentrated training programs are organized for science teachers, especially. With the inclusion of planetariums and science centers outreach activities have become more productive in the recent years.
\end{abstract}

Keywords: public outreach - education - planetariums - science centers.

\section{Introduction}

Astronomy public education and outreach activities are mostly organized by astronomy and related departments. Small university observatories and TÜBÍTAK National Observatory are participating to those events sometimes as the main organizer and sometimes as the supporting institution. A list of astronomy departments and physics departments with astrophysics faculty members are listed in Table 1. Distribution of those institutes in the country can be seen from Fig. 1 (Eker et al., 2013).

University clubs also play a very important role in outreach activities. They organize public nights, school visits and more together with the coordination of faculty members.

\section{Public Nights, Seminars and Conferences}

Many astronomy departments regularly organize public nights. A typical public night includes a popular talk, visit to observatory and telescope viewing. Recently Istanbul University Observatory has started an event series called "Starry Nights". This 
particular event has been organized since February 2017 on last Friday of every month. An average of 300 people have participated to those events with an exception of total lunar eclipse on July, 27th 2018 where nearly a thousand people participated. Thanks to the establishment of a planetarium within the astronomy department, "Starry Nights" has become a very attractive event for astronomy enthusiasts.

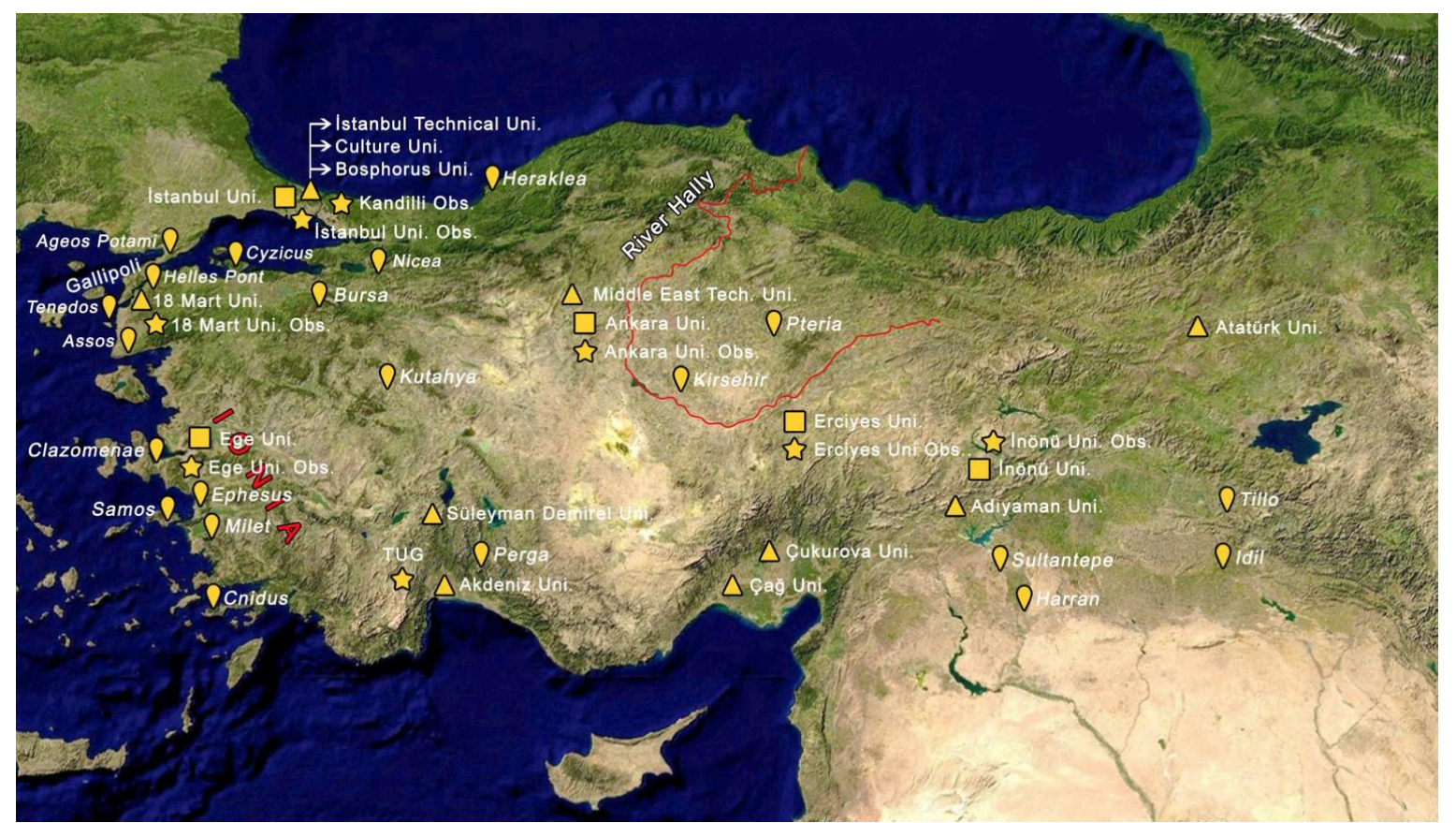

Figure 1. Map of astronomical institutions and observatories in Turkey (Eker et al., 2013). Squares denote astronomy and space sciences departments, triangles denote physics departments with astrophysics branch and space sciences and technologies departments, stars denote observatories and balloons denote ancient sites with a connection to astronomy.
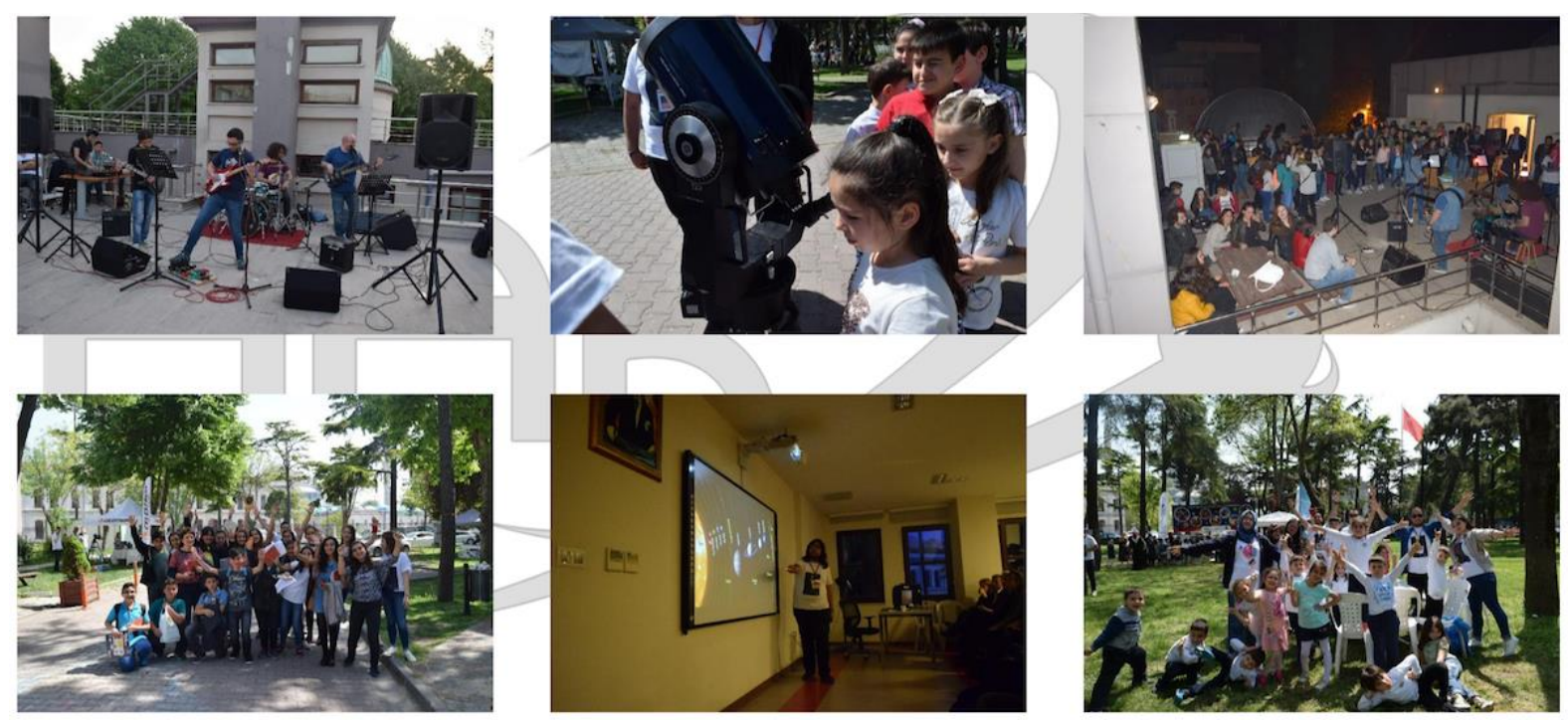

Figure 2. A collage of photos from public events organized by Amateur Astronomers Club (AAK) of Istanbul University. 
Table1. List of astronomy and related departments in Turkey

\begin{tabular}{|lcl|}
\hline \multicolumn{1}{|c}{ University } & Department & City \\
\hline Istanbul University & Astronomy and Space Sciences & Istanbul \\
Ankara University & Astronomy and Space Sciences & Ankara \\
Ege University & Astronomy and Space Sciences & Izmir \\
Erciyes University & Astronomy and Space Sciences & Kayseri \\
Inonu University & Astronomy and Space Sciences & Malatya \\
Onsekiz Mart University & Space Sciences and Technologies & Canakkale \\
Akdeniz University & Space Sciences and Technologies & Antalya \\
Ataturk University & Astronomy and Astrophysics & Erzurum \\
Bosphorus University & Physics & Istanbul \\
Sabanci University & Physics & Istanbul \\
Cukurova University & Physics & Adana \\
Istanbul Technical University & Physics Engineering & Istanbul \\
Adiyaman University & Physics & Adiyaman \\
Onsekiz Mart University & Physics & Canakkale \\
Middle East Technical University & Physics & Ankara \\
Yildiz Technical University & Physics & Istanbul \\
& & \\
\hline
\end{tabular}

\section{Radio and TV Programs}

Astronomy and space are almost hot topic for media. Turkish astronomers frequently show up in the TV programs, participate to radio interviews. There are sometimes newspaper articles and interviews, as well but in the current era TV and radio are more widespread. Especially when there is a celestial event like a comet or an eclipse, those media channels show a big interest to astronomers.

\section{Magazines and Newsletters}

The oldest astronomical magazine was the "Gökyüzü" (The Sky) of the Turkish Astronomical Society (TAD) that was first published in 1957. At that time, "Gökyüzü" was also the main communication way for TAD and was making announcement about the society. Later on, it became difficult to publish such a magazine. There was another attempt from the astronomers of the Ege University with a title of "Science". This "Science" magazine could continue to its life from 1965 to 1971.

A third attempt was again from Ege University. University's astronomy club ("Ege Üniversitesi Astronomi Topluluğu"; EÜAT) published an astronomy magazine. 
This magazine was published from 1992 to 1999. It contained recent news and observations, amateur studies and some practical information for backyard observers.
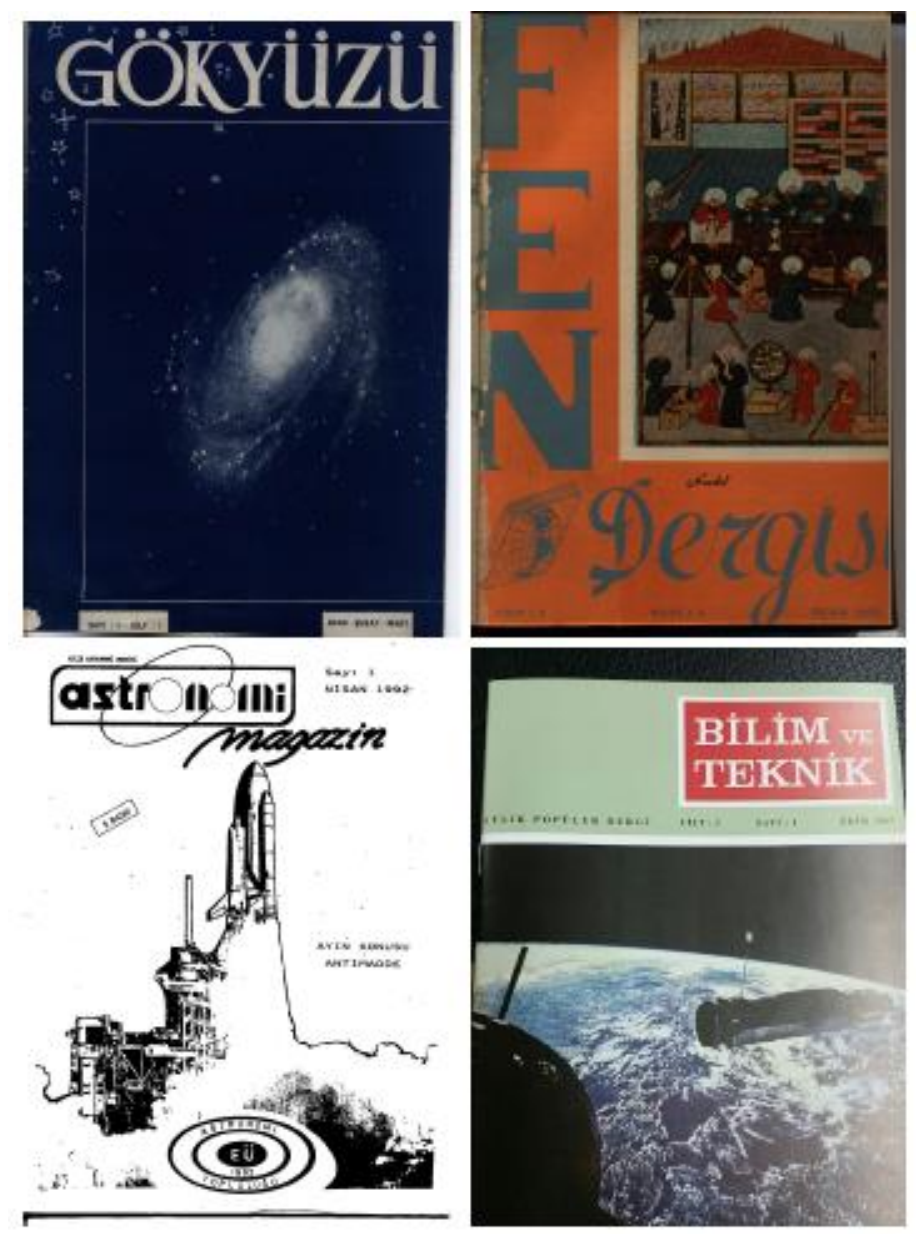

Figure 3. First issues of the some major astronomy and science magazines. Upper left: Gökyüzü (1957); upper right: Science Magazine (1965); lower left: Astronomy Magazine (1992); lower right: Science and Technology (1967).

"Gökyüzü" magazine of the Turkish Astronomical Society later published again in 1999-2000 but unfortunately had to stop. Finally, with the driving force of Year of Astronomy in 2009, the magazine started to be published but this time electronically. Since then, it has been published as an e-newsletter. All issues of the "Gökyüzü" enewsletter can be accessed via the Turkish Astronomical Society's website (http://www.tad.org.tr/e-bulten).

The long lasting magazine in Turkey is the "Science and Technology" (http://www.bilimteknik.tubitak.gov.tr/) which is published monthly by the Scientific and Technical Research Council of Turkey (TÜBÍTAK). "Science and Technology" is published since 1967 and covers a wide range of topics. However, astronomy and space are always present in the magazine. 

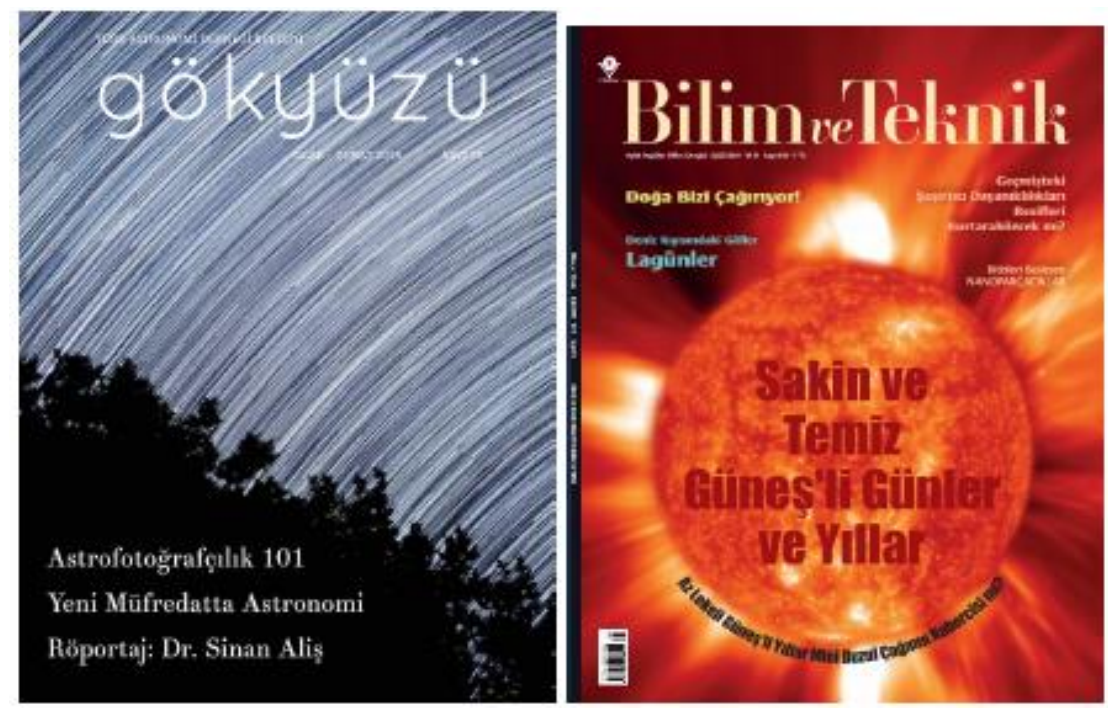

Figure 4. Latest issues of Gökyüzü (Jan-Feb 2018) and Science and Technology (Sep 2018) magazines.

\section{Astronomy Schools}

The first observatories of the Turkish Republic, with chronological order, are Istanbul University Observatory, Ankara University Observatory and Ege University Observatory. These observatories organize summer and winter schools for children at various ages.

Ege University Observatory organized summer schools for general public during 1996-2011. This summer school was a 5-day activity and participants were accommodating at the observatory. While there were lectures on different aspects of astronomy during the day, there were night-sky observations at nights. A total of 1000 people attended this summer schools in the fifteen years period.

Ankara University Observatory organizes one-day children astronomy schools at weekends. Depending of the program different age groups are covered throughout the year. A similar activity for children is organized in Istanbul University Observatory but for longer duration; one week or two weeks. The so-called "children university" is organized two times per year, one in the semester break at February and the other in the summer vacation, mostly in June or July.

TÜBITAK National Observatory (aka. TUG) has been organizing summer internship for undergraduate students in astronomy, astrophysics and physics. Students spend a week at the observatory ( $2500 \mathrm{~m}$ a.s.l.) and gain experiences about astronomical research and instrumentation. Based on the ranking with their GPAs and recommendation letters, observatory selects 4-5 students for each period. For each period, a faculty member from Turkish universities mentoring students during their stay. A very similar internship/training has started to be organized by the 
Eastern Anatolia Observatory Project (aka. DAG) where a $4 \mathrm{~m}$ optical + infrared telescope will be built and will become operational in 2020. This is the largest astronomical and even fundamental science project in Turkey. Since DAG Telescope will be equipped with state-of-the-art instruments and novel technologies, it is very important that the Turkish astronomy students get experience and knowledge about them as early as possible. Undergraduate student trainings started at TUG in 2008 since then more than 200 students are participated to the program; at DAG it is started in 2018 and for the first year 16 students participated.


Figure 5. A collage of photos from the different astronomy schools that organized by Istanbul University Observatory and Ankara University Kreiken Observatory.

\section{Star Parties and Astronomy Festivals}

The first public star party was organized in 1998 by TÜBÍTAK in the outskirts of Mount Bakirli where the national observatory is located. Since 1998, every summer the largest astronomical festival has been organized by TÜBÍTAK and recently this organization is carried out by the national observatory. 21st of this sky festival was organized in 2018. Each year roughly 400 people participates to the event. The event is organized in three days. During daytime there are seminars, workshops, forums and several activities; whereas observations at night.

After this star party which is organized by TÜBÍTAK, there are several similar organizations emerged. People attended to the first star parties, gained experiences, learned how to make telescopes and learned how to observe. These people then started to instruct others in different events. Especially, a very efficient amateur 
group of people gathered for the amateur telescope making. In 2009, during the Year of Astronomy, this group led to the making of 100 Newtonian telescopes at the same time in a week.

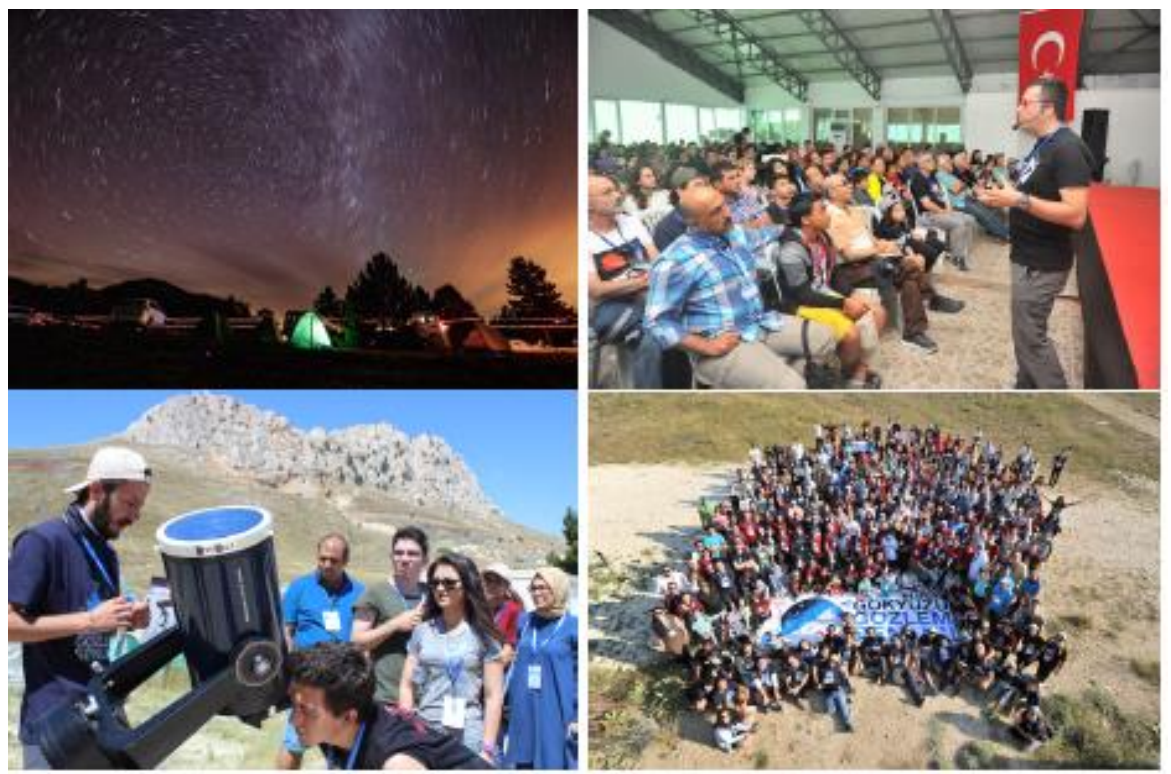

Figure 6. A collage of photos from star parties.

- Amateur Astronomers Club (AAK), Istanbul University, (http://www.aak.istanbul)

- Astronomy Research Group (ASART), Ankara University, (http://asart.science.ankara.edu.tr)

- Amateur Astronomy Club (AAT), Middle East Technical University, (http://www.gokyuzu.org)

- Astronomy Club (ASTER), Erciyes University, (http://aster.erciyes.edu.tr)

Among these festivals, the one that is organized by AAK of Istanbul University is the oldest. Every year in May, AAK organizes a week-long event includes public seminars, observatory visits, planetarium shows and telescope viewing. In 2018, 27th of the event was organized. During this "May Festival" approximately 2500 people including school kids visit Istanbul University Observatory. AAK's "May Festival" by far the largest student organization in Turkey. Besides such large events, university clubs also organize public nights for special astronomical events. Sometimes, university clubs are invited by schools and they organize talks and telescope viewing for various classes in the school. Between September 2017 and September 2018, AAK reached totally 4000 people in their events. 


\section{Planetariums and Science Centers}

Planetariums became a very efficient way for science communication. Nowadays, there are almost one science center in each city of Turkey. This is a Ministry of Education and TÜBITAK common project to build a science center for every city. Planetariums are one of the essential unit in these science centers. Moreover, there are many individual planetariums besides these science centers. Most of these planetariums are belong to private schools or municipalities. A detailed list of planetariums in Turkey is given below. The list is not complete as there are many other institutes are under construction. Most of the planetariums in this list are based on single projector equipped with fish-eye lens. Therefore, their image quality are not superb. However, Uzayevi in Eskişehir and City Planetarium in Gaziantep are equipped with high quality projectors and opto-mechanic systems.
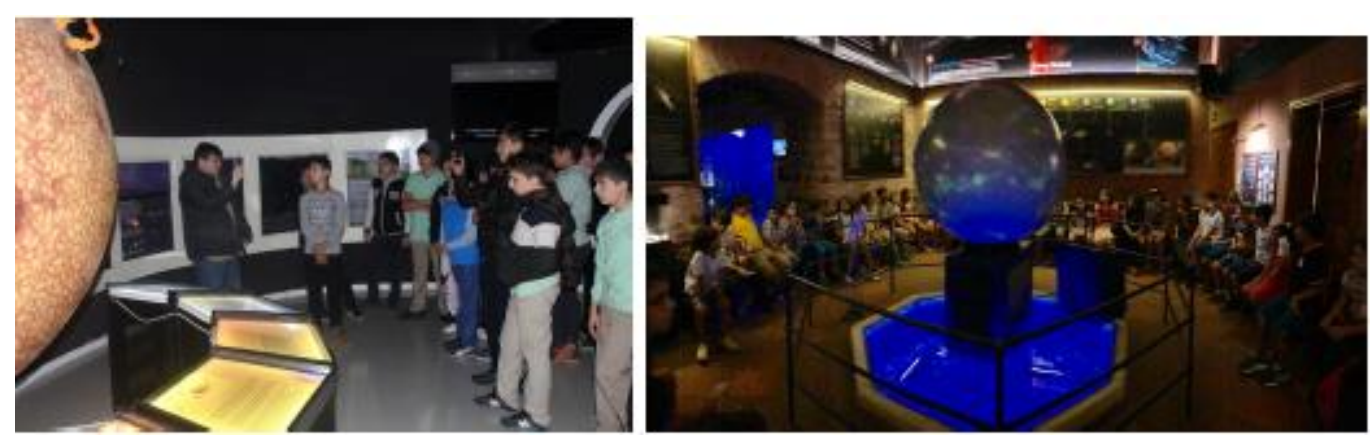

Figure 7. ISTEK Belde School Astronomy Museum (left) and Koç Museum (right).

- Istanbul University Science Faculty E.C.A. Planetarium, Istanbul

- Kayseri Science Center Planetarium, Kayseri

- Konya Science Center Planetarium, Konya

- Okyanus High School Planetarium, Istanbul

- Amasya Planetarium, Amasya

- Bursa Science and Technology Center Planetarium, Bursa

- Cacabey Planetarium, Bursa

- Çağ University Planetarium, Mersin

- Darüşşafaka Educational Institutions Planetarium, Istanbul

- Naval Academy Planetarium, Istanbul

- Uzayevi, Eskişehir

- Gaziantep Municipality Planetarium, Gaziantep

- Ōzel Türk High Schools, Izmir

- Ondokuz Mayis University Planetarium, Samsun

- Rahmi M. Koç Museum Planetarium, Istanbul 
- Sancaktepe Science Center Planetarium, Ilstanbul

- Elazğ Science Center Planetarium, Elazğ

- Ses Schools Planetarium, Samsun

- Tuzla Municipality Planetarium, Istanbul

- Istek Belde Schools Planetarium, Istanbul

- Serdivan Municipality Planetarium, Sakarya

- Ali Kuş̧̧u Planetarium, Istanbul

- Üsküdar Municipality Science Center Planetarium, Istanbul

Recently, a new 4K planetarium begun its operations in Istanbul University Astronomy and Science Department (http://astronomi.istanbul.edu.tr/bilimtoplum/). This very new planetarium uses multi-projectors and video mapping techniques to ensure the high image quality (Saygac and Alis, 2018). For the moment, there is not a centralized database for the visitors of these planetariums. Visitor statistics of Istanbul University Planetarium can be taken as representative, such that between February 2018 - July 20188143 people have visited the planetarium.

Regarding astronomy outreach activities carried out in planetariums, translation efforts have also been started. Some of the publicly available planetarium shows are already translated into Turkish.

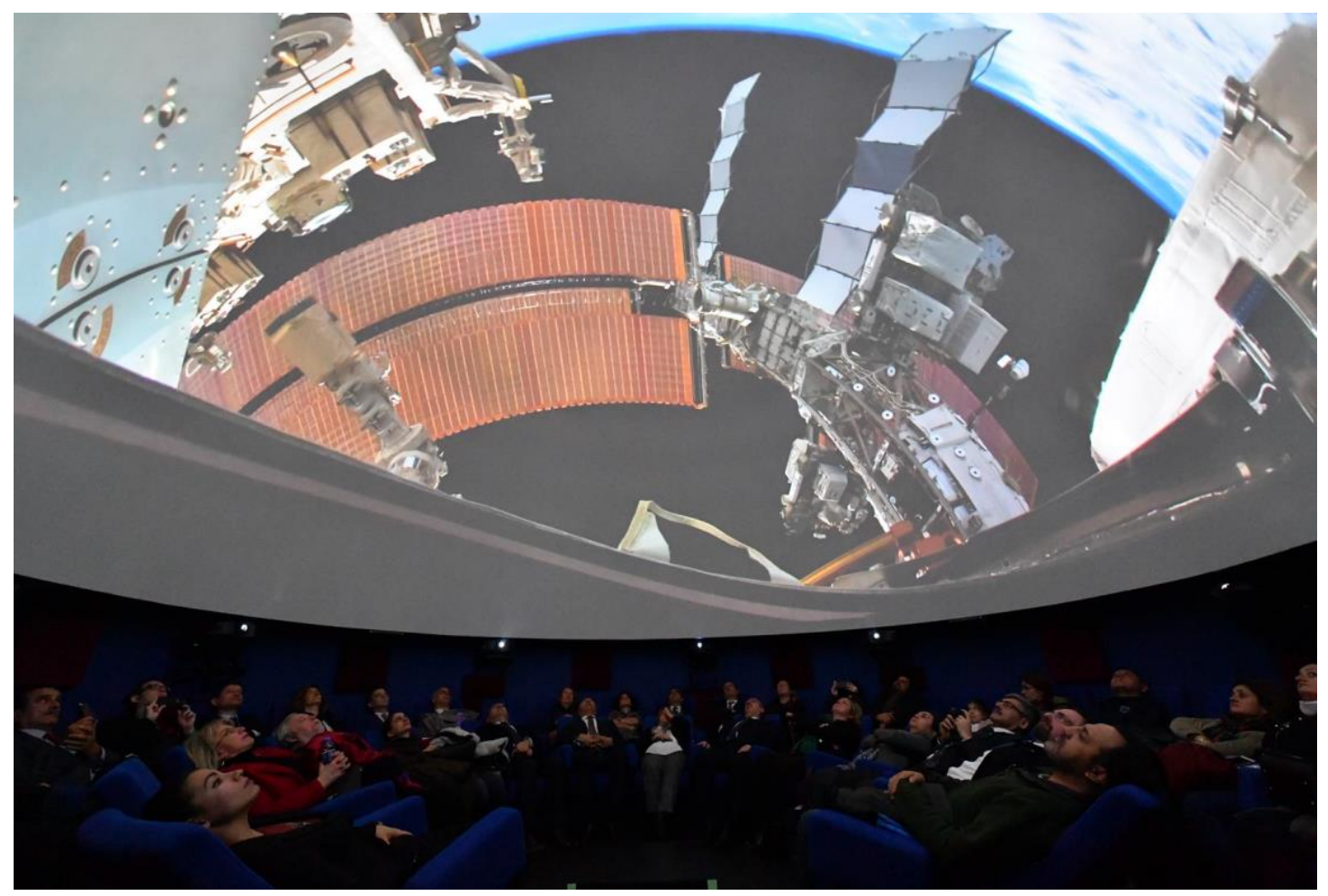

Figure 8. Istanbul University's 4K planetarium with multi-projector system. 


\section{Teacher Training Programs}

As it is the case for many countries, astronomers are not responsible people in high school teaching activities. In many schools science or math teachers teach astronomy and related topics. Consequently, either those topics are not well covered due to lack of knowledge or not covered at all. Taking the opportunity of 2006 total solar eclipse, TÜBITAK National Observatory (TUG) and some astronomers made an agreement with the local authorities for education in Antalya and organized a teacher training just before the eclipse take place. Later on, this group of astronomers continued their efforts on their own. An initiative called "Astronomi Ōgretmen Seminerleri - AŌS" (Astronomy Seminars for Teachers) became very popular and efficient in the recent years. A group of astronomy professors and some experts on science education organize these events in different cities of Turkey. Latest training is planned to be on November 16-18, 2018 in the city of Aksaray (central Anatolia). Details of this program can be found on their website (http://www.astrobilgi.org/tag/astronomiogretmen-seminerleri).

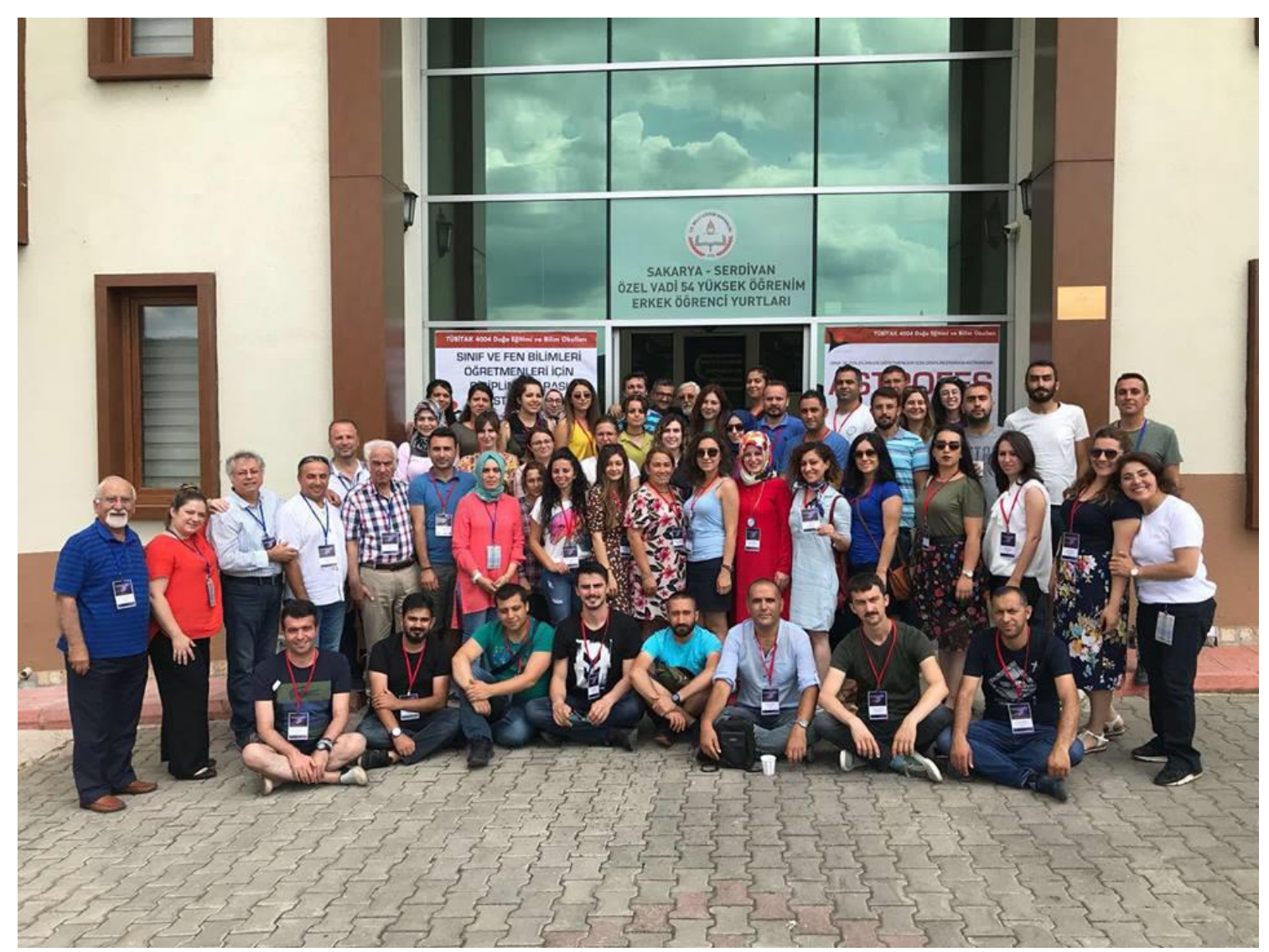

Figure 9. One of the latest teacher training (AŌS) organized in the city of Sakarya. 
Independently, Turkish Astronomical Society (TAD) carries out a similar teacher training program in coordination with the International Astronomical Union; Galileo Teacher Training Program (GTTP). GTTP program that is taken care by TAD is not as efficient as AŌS. Moreover, professors are involved with AŌS program are also member of TAD. Therefore, there are discussions to combine these efforts in order to save energy and improve the efficiency. This is probably going to be happen in the framework of IAU100 activities in 2019.

\section{Summary}

There is a great diversity of activities in Turkey for astronomy outreach. Nowadays, it is the general understanding that professional astronomers, astrophysicists should also support these activities besides their research and teaching activities. With time more and more astronomers are getting involved with outreach, however these activities are mostly done by young researchers. In Turkey, astronomy clubs at universities are very efficient to reach general public and school kids. Almost every observatory organize public nights which include popular astronomy talks, telescope viewing and similar activities. Inauguration of planetariums made also possible to reach people with ease. There is a very strong interest by public to the planetariums. Therefore, Ministry of Education and related government bodies decided to spread science centers all over the country. Pilot projects already started in some major cities like Konya, Gaziantep, Kocaeli etc. The plan is to establish a science center for each city.

All these activities are very rich and it is very exciting to see that public are very interested in science and specifically in astronomy. However, these efforts are not performed in coordination with each other. After all these experiences, it can be said that a good coordination and networking is needed to improve the efficiency. Therefore, Turkish Astronomical Society can be filled this gap by acting as a governing body of these activities. There is a plan for the 2019 to establish a portal for astronomy outreach activities within the framework of IAU100 celebrations.

Acknowledgements. SA is grateful for Byurakan Astrophysical Observatory for their hospitality.

\section{References}

Eker, Z. et al., 2013, Astronomy in Modern Turkey, In Andre Heck (Ed), Organizations, People and Strategies in Astronomy Vol. 2, Venngeist, Duttlenheim, 195 Saygac, A. T., Alis, S., 2018, Planetarian, vol. 47, no. 17 